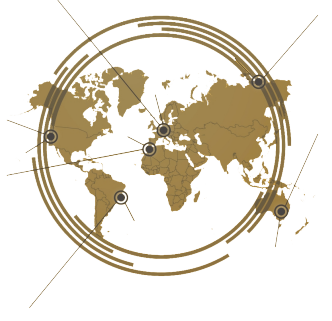

\title{
Synchronous online discussion: Teaching English in higher education amidst the covid-19 pandemic
}

\author{
Aji Budi Rinekso*, Ahmad Bukhori Muslim \\ English Language Education Study Program, School of Postgraduate Studies, Universitas Pendidikan Indonesia
}

During the outbreak of Covid-19 pandemic, many educational institutions have adapted various online teaching modes. However, studies exploring the employment of synchronous online discussion for teaching English in higher education context is still limited. This study aimed at investigating EFL university students' perceptions and challenges on the use of synchronous online discussions. Employing virtual observations and semistructured interviews, five Master students of English education study program of a public university in Bandung participated in this study. Data were based on three domains of communication types for e-learning; content-related, planning of tasks and social supports. The findings showed that the students had positive response to the employment of synchronous online discussion. They believed that synchronous online discussion was a good online teaching mode where task negotiation, task planning, opinions, questions and answers can be done easily. In addition, they could improve critical thinking and writing skills as well as get social supports. Meanwhile, poor internet connection and misunderstanding of tasks became the challenge.

Keywords: Synchronous online learning, Teaching English, Higher education

\section{INTRODUCTION}

Looking ahead to the decision of closing face-to-face interactions, most of the universities in Indonesia employed online learning to cope this challenge. Online learning refers to the new format of learning delivery which allows the technological tools such as computer and internet bridging the transfer of learning materials (Carliner, 2004). In recent years, technological development has allowed universities to conduct innovative instructions with the involvement of online learning either fully or partially. However, Covid-19 caused emergency situation has forced universities to massively employ online learning in order to maintain instructions. Generally, online learning can be categorized into three learning environments, namely synchronous learning environment, asynchronous learning environment, and hybrid learning environment (Perveen, 2016).

Synchronous learning environment refers to the real-time online learning which facilitates students and teachers to interact at the same time or live (Salmon, 2013; Shahabadi and Uplane, 2015). Some examples of synchronous learning environment include video conferencing, teleconferencing, live chatting, and live-streaming lectures. The benefits of synchronous online learning relate to the increase of students' engagement and motivation because teachers can directly monitor the learners' responses during the learning process (Hrastinski, 2008). This is confirmed by a study which proved that synchronous learning environment can promote and 
enhance students' engagement levels as well as the quality of the learning process (Wdowik, 2014). Conversely, asynchronous learning environment provides more flexible time for students and teachers to conduct the learning process since it is not limited by time, place and classroom (Mayadas, 1997). In this case, asynchronous learning environment facilitates the learners and teachers that cannot be online at the same time (Hrastinski, 2008). Email, online modules, virtual libraries, lecturers' online notes, lecturers' blogs, online discussions boards or social media platforms are the examples of asynchronous learning environment. The hybrid learning environment is the combination of synchronous and asynchronous learning environment in order to get the most preferable learning environment (Perveen, 2016).

The changes of learning modes from face-to-face interaction to online interaction demands English lecturers to adapt to this situation. They have to find any appropriate teaching methods that suit to the online learning mode. One of the most common method is online discussion. Online discussion provides some benefits such as real-life audience, current information and increased topic focus Sutherland-Smith (2002). Through online discussions, lecturers and students can be connected directly and easily without worrying about their distances. In addition, through internet access, students can browse the most updated information and this will encourage the students to give the best opinion in the discussions. As a result, the students will be more focused and engaged with the topic available in the discussions. Likewise, online discussions also encourage students to share experiences and learn from them each other (Parra, 2000). This helps the lecturers to provide live and constructive learning environment for developing the students' knowledge. As explained in the previous paragraph, online learning can be conducted within three modes of learning environment namely synchronous, asynchronous, and hybrid learning environment. Hence, the current study focuses on online discussions done in synchronous learning environment or simply called synchronous online discussions. This mode of learning environment is considered in this study since synchronous online discussion are increasingly becoming trends in higher education lately (Duemer et al., 2002).

As online discussion becomes alternative way for today's language teaching, we could define discussions as the process of interaction for sharing ideas and opinions within a group of people Arends (1997). Moreover, people do discussions because of some reasons. In line with this idea, Gulley (1968) argued that discussions aim for enlightenment and policy determination. When the aim is enlightenment, the group members systematically define, analyze and exchange information. Meanwhile, the group members will systematically define, evaluate possible solutions and come up with an agreement if the aim is for policy-determination. In English language learning context, discussion is likely aiming for enlightenment as well as improving students' English proficiency.

There are four categories of approaches in learning through discussions. The first is to check students' ideas. This aims to make sure that the students were in the right track for doing their learning process as well as understanding learning materials. The second is to acquire ideas. It means that through the discussions, both teachers and the students can gather ideas on a certain topic that they discuss. The third is to develop ideas. When students do the discussions, they share ideas each other and from this they can start to improve their own thinking. Lastly, discussions allow students to challenge their ideas and beliefs. Through this way, the students will get more complete understanding on a topic that they discuss (Ellis et al., 2006). In short, teachers can use discussions for teaching English based on various approaches.

Online discussions can also be aligned to Bloom's Taxonomy (Ragupathi, 2018). In the stage of remembering, students recall facts and key concepts. Then, in understanding stage, they will explain ideas or concepts which is followed by discussing and summarizing the key concepts. In applying stage, students will use knowledge/information in new ways through manipulating, experimenting and problem solving. Meanwhile, drawing connections among ideas as well as organizing ideas refer to analyzing stage. Next, students will come to the stage of evaluating by justifying, contrasting, comparing and reframing the ideas. In the stage of creating, they will produce new ideas based on their own prior knowledge and thoughts. This shows that online discussions support the process of students' cognitive development.

Using online discussions for teaching English is the best choice. Lots of benefits are offered by online discussions. They are (1) demonstrating knowledge of key concepts, (2) stimulating higher order critical thinking skills, (3) encouraging peer interaction and team work, (4) promoting thoughtful reflection, (5) achieving social interaction and community building, and (6) encouraging student-generated discussion topics (Ragupathi, 2018). Those benefits will elevate students' English proficiency, cognitive aspect and social skills. Likewise, online discussions could boost students' learning performances Sutherland-Smith (2002) as they tend to have better preparation of choosing appropriate vocabulary and completing reading tasks in online discussions rather than in face-toface classroom discussions.

Furthermore, some studies have already been conducted under the issue of online discussions. The first study explored how online forum discussions can promote writing skill pedagogically Jose and Abidin (2016). The findings reveal that through online forum discussions learners can improve their writing skills by sharing ideas and checking grammati$\mathrm{cal} /$ spelling errors each other. In addition, it was suggested for the English teachers to make clear ground rules for the discussions including the strict use of L2 (English) as well as the prohibition for jokes and insulting issues. The second study investigated ESL learners' interaction in an online discussion via Facebook Omar et al. (2012). The results showed that the ESL learners had positive responses towards the use of Facebook for online discussions and it was believed that conducting online discussions in Facebook could boost learners' confidence and 
collaboration during the learning process. Lastly, a study confirmed that online discussions can enhance students' critical thinking (Williams and Lahman, 2011). The study found that through online discussions students were more engaged with the lesson. Even some students who often reluctant to speak in face-to-face class would be seen more active in online class. The higher engagement resulted on the better way of students' thinking and this led to the enhancement of critical thinking.

Given these points, we can see that online discussions are beneficial for language teaching. Thus, the current study tried to take another focus by exploring EFL university students' perceptions and their challenges on the use of synchronous online discussion for their instructions. By focusing on this issue, the present study led to a basic consideration for language teachers in adopting synchronous online discussions in their teaching practices. Two research questions were administered in this study.

1. What are the EFL university students' perceptions on the employment of synchronous online discussions?

2. What are the challenges faced by EFL university students during the synchronous online discussions?

\section{METHODS}

Since this study tries to explore how EFL university students perceive the application of synchronous online discussions, a qualitative case study was employed to be the procedure for conducting this research. Many scholars (Saldana, 2011; Mackey and Gass, 2005; Merriam and Tisdell, 2016) have confirmed that qualitative study including a case study (Creswell and Poth, 2016; Yin, 2016) aims at uncovering humans' life including activities, experiences and phenomena where descriptive data are dominantly used, rich and very detailed. Typically, case study puts a person, community or organization as a single case for its focus of the study (Creswell and Poth, 2016). Here, the study captured a class functioning synchronous online discussions as its mode of learning to be the case.

Moreover, five postgraduate (master program) EFL university students of a public university in Bandung, Indonesia, participated in this study. Prior to the study, the students had joined a course which employed synchronous online discussions. The discussions in the course were in form of live chat through WhatsApp Groups (WAG). As qualitative research tends to employ purposive sampling to meet its goal of inquiry (Hamied, 2017), the selection of the participants was conducted purposively in regards with some reasons including class participation and willingness. All of the five participants joined more than $80 \%$ of the total meetings (16 meetings), followed the class sessions till end, and welcomed to be invited as the participants of this study. Next, data were collected through virtual observations (participatory) and virtual interviews (semi-structured). In this case, the researchers did the observations by joining into the online group discussions directly. Meanwhile, the researchers interviewed the participants virtually through WhatsApp in order to maintain the physical distancing. The interviews lasted for around 15-20 minutes for each participant and the participants' responses were sent via WhatsApp voice notes. The process of collecting the data was conducted during March - May 2020.

The collected data were analyzed thematically following the process of familiarizing data, coding, memoing, generating themes, relating themes and writing them up. Here, the codes and themes were evolved in regards with the dimensions of elearning namely content-related, planning of tasks and social supports, further explained in next the paragraph. The analysis also corresponds to the general stages of qualitative data analysis suggested by Miles and Huberman (1994), Miles et al. (2014) namely data, data display, and drawing and verifying conclusions. Talking about researchers' positionality, the main researcher did not have power over the participants as he was the part of the cohort, sharing similar authority with the participants. While the second researcher might have power as he was the instructor, the fact, the second researcher was only involved in data analysis process after data collection. Here, the participants were positioned to deal with the main researcher only, and they did not know about their instructor's involvement on this study. Likewise, the researchers stayed to maintain objective relationship with the participants throughout this study.

A model of communication types for e-learning suggested by Hrastinski (2008) and Haythornthwaite (2002) was employed as the basis of the observation and interview guideline constructions. The model consists of three types of communication exchange, namely (1) content-related, (2) planning of tasks, and (3) social supports. Content-related refers to the exchange of information about the learning materials discussed such as asking-answering questions, sharing information, and expressing ideas. Secondly, planning of tasks deal with the task management activities including planning work, allocating tasks, and reviewing drafts. Meanwhile, social supports consist of learners' emotional expressions such as using emoticon, giving advice and expressing feelings.

\section{RESULTS AND DISCUSSION}

This study deals with an investigation on how EFL university students perceived synchronous online discussion used in their instructions during the Covid-19 pandemic. The researchers invited five master students majoring English language education study program to participate in this study. They were in the second semester and taking a course which employed synchronous online discussion (live-chat discussions through WhatsApp Group). The course has 16 meetings where the first 4 meetings were conducted in face-to-face classroom (before school closure policy administered in Indonesia) and the rest was done online through live-chat discussions in WhatsApp 
Group. In terms of the schedule, the course was held every Wednesday at 10.00 A.M. In addition, this course has 3 credits and focuses on discussing issues about analyzing data in qualitative research. Lastly, English was used as the medium instruction during the class sessions.

The researchers did virtual observation during the last 12 meetings which were conducted online via live-chat WhatsApp Group (WAG). From the observation, the researchers gained rich data related to the instructional situations. As mentioned in the previous section, this study adopts a model of communication types for e-learning consisting of content-related, planning of tasks, and social supports. Therefore, a number of activities during the online class were recorded on the basis of those three types of communication. Table 1 shows the summary of the online class activities.

Firstly, content-related belongs to the lecturer and students' interactions with learning materials. The lecturer opened class by greeting the students. At the same time, he also checked students' attendance or participation by listing students' names in the WAG. Reviewing previous materials was also done by the lecturer to check the students' memory. In terms of materials delivery, mostly, the lecturer used screenshot (pictures) of power point slides, charts, tables and texts. To check students' understanding as well as students' attention, the lecturer asked every student by mentioning the students' name. This was an effective teaching strategy to cope the lack of attention in online learning since some students during the online learning might only open the WAG without following the discussions. To train the students' critical thinking, the lecturer also served analytical questions such as "what is your understanding about...?", "how do you categorize/confirm/clarify/justify...?", "why do you think that...?".

Secondly, activities that are related to the management of assignments refer to the planning of tasks. In this case, there were two main activities done by the students in planning their tasks, namely task confirmation and task negotiation. In task confirmation, the students tried to clarify about the assignments given by the lecturer. For example, they asked about citation/reference style, the layout of journal article, and instrument validation. This happens when some students were still unsure about their understanding on the tasks' guideline/rules. Meanwhile, task negotiation happens when the students need dispensation. For example, they negotiate for the tasks' complexity and submission deadline.

Lastly, social supports reflect on how the emotional expressions and engagement can be maintained during the discussions. The majority of the students showed active participation during the class sessions. They looked responsive for responding to the lecturer's questions as well as asking questions to the lecturer when they were still unsure about certain materials. In every closing discussions session, the lecturer said thanks for joining and participating in the class. Meanwhile, the students responded it by saying thanks and giving hopes. They also added emoticon, mostly the thanking emoticon (folded hands).

\section{Perception on the Employment of Synchronous Online Discussion}

To gain deeper data related to the participants' perceptions on the use of synchronous online discussion in their instructions, the researcher did virtual interviews. The information gathered from the interviews was based on the model of communication types for e-learning, including content-related, planning tasks social supports (Hrastinski, 2008; Haythornthwaite, 2002). Table 2 shows the summary of data gathered from the virtual interviews. A number of key issues are presented based on the three types of communication for e-learning. This section focuses on key issues related to the participants' perceptions while the participant's challenges are discussed in the next section.

Talking about the effectiveness of using synchronous online discussions, most of the participants believed that this way of teaching was quite effective to be conducted in this pandemic situation. Obviously, online discussions allow students and the lecturer to interact with, discuss materials as well as maintain physical distancing at the same time as this mode of learning does not require close-range physical interaction. Next, live-chat discussions through WAG was easily to be conducted since all students were already familiar with WhatsApp. This application also does not require the use of big data. Thus, it is light and simple application. Additionally, live-chat discussions allow students to get feedback directly from the lecturer.

In the same way, some studies (Murphy and Collins, 1998; Lee, 2002) discussed benefits of live-chat discussions. The benefits provide a sense of immediacy where learners and teachers can share opinions, viewpoints as well as clarify misconceptions in a real time. Moreover, they are allowed to fully use the target language to negotiate both meaning and form in a social context, in regards with topics being discussed. However, some participants argued that the lecturer also played an important role for succeeding the teaching process using synchronous online discussions. In this case, the lecturer is demanded to be active for leading the beginning until the end of the discussions. Social interaction should also be maintained in order to produce live interaction during the class.

"The lecturer can lead the discussions inter-
actively. Therefore, the discussions are quite
effective and every student get involved in
the discussions"

During the discussions, students have opportunities for giving opinions, asking and answering questions. Likewise, this supports the idea of learner-centered approach in teaching English (Nunan, 2012; Liu et al., 2006; Li et al., 2005). In fact, at the same time, live-chat discussions operate teacher-centered approach as the lecturer had to manage and direct the discussions. Yet, the discussions were essentially performed by the students. The lecturer only acted as a facilitator. Initially, the lecturer guided the students to open class discussions. $\mathrm{He}$ 
TABLE 1 | The Result of Virtual Observation

$\begin{array}{ll}\text { Communication types } & \text { Class Activities } \\ \text { Content-related } & \text { The lecturer starts discussions by reviewing previous materials. The lecturer explains } \\ \text { materials by showing pictures/graph/texts. The lecturer asks students by mention- } & \text { ing students' name. The students respond to the lecturer questions. The students ask } \\ & \text { questions to the lecturer. } \\ & \text { The students confirm/clarify tasks given by the lecturer. The students negotiate the } \\ & \text { tasks such as the tasks complexity and submission date. } \\ \text { Planning of tasks } & \begin{array}{l}\text { Students participate actively during the discussions. Students show emotional } \\ \text { expressions such as emoticon, supports or hopes. Students look responsive during } \\ \text { the discussions. }\end{array}\end{array}$

TABLE 2 | The Summary of Virtual Interviews

\begin{tabular}{|c|c|c|}
\hline Communication types & Key Issues & Category \\
\hline \multirow[t]{2}{*}{ Content-related } & $\begin{array}{l}\text { The use of synchronous online discussions Opinions, Ques- } \\
\text { tion and Answer (Q \& A) delivery Critical thinking Lan- } \\
\text { guage skill (writing, grammar and spelling) }\end{array}$ & Perception \\
\hline & Problems in Q \& A & Challenge \\
\hline \multirow{2}{*}{ Planning of tasks } & Tasks negotiation and planning & Perception \\
\hline & Problems in planning tasks & Challenge \\
\hline Social supports & Emotional expressions Psychological effects & Perception \\
\hline
\end{tabular}

asked every student by mentioning students' name and gave the students opportunity to respond to the questions. After each topic had been discussed, the lecturer gave students opportunity to ask some questions, give opinions or confirming statements. Mostly, the participants respond to the lecturer's questions when the questions were addressed to them. However, sometimes, the lecturer asked questions addressed for all students. In this case, everyone can freely answer the questions or add their opinions related to the questions. This situation was almost similar to face-to-face classroom where each student gets opportunity to deliver questions and opinions.

"When answering or asking questions and giving opinions, I tend to wait for the lecturer giving me questions. Oh ya, sometimes I give opinions when the questions are addressed for all students"

Live-chat discussions allow students to enhance their critical thinking. This happens when the lecturer gave analytical questions such as how and why. With these kinds of questions, students tried to answer the questions based on some facts, data, theories which were combined with their perspective or understanding. In this case, live-chat discussions play an important role in fostering students' comprehension and knowledge of the discussed topics as well as training them to express their ideas into meaningful way (Macknight, 2000). The participants respond positively about the way their lecturer gave critical questions during the discussions. In addition, the students were not only answering analytical questions from the lecturer but also analyzing their friends' answers. As a result, all students always stay focused on following the whole discussions. Correspondingly, this result reinforced the findings of previous study (Williams and Lahman, 2011) where students had opportunities to think more critically beyond others as they could read others' responses, ideas or opinions.
"Yes of course. It is because the lecturer stim- ulates us with critical questions"
"I think it trains our critical thinking. For example, when we tried to analyze other stu- dents' answers"

Live-chat discussions which demand students to type answers/responses quickly can improve their writing skills including the accuracy of using grammar and spelling. This correspond to what previous study Jose and Abidin (2016) claimed where online discussions potentially encourage participants to perform better grammar checking and awareness. Although the participants were master students where the language skills were not the main focus of the teaching, they have to perform high quality of writing via live-chat discussions. Some of the participants checked their spelling by electronic dictionary and third-party application in keyboard. The participants also re-read their writing before sending it to the WAG. In terms of language style, the participants admitted that they can improve it by observing other friends writing. The lecturer also reminded the students when they had mistaken in their writing. In line with this, a study conducted by Liang (2010) found that synchronous online peer response group supports the teaching of writing. It enables students to collaboratively brainstorm, share and review texts. 
"Yes. It improves my writing. I often look at other friends writing and it motivates me to improve my language style"

Moreover, tasks also become interesting issue to be discussed in the last discussions. Usually, the lecturer announced the tasks in the last session of the discussions. The tasks were about writing introduction of a paper, writing literature review, coding interview data, and writing a thesis proposal. Most of the participants agreed that they can negotiate the task submission deadline to the lecturer. Then, commonly the lecturer gave extra time for finishing the tasks. In this case, task negotiation can enhance students' achievement, motivation, and involvement as well as build close interaction between the lecturer and students (Tuan, 2011). Meanwhile, they planned the tasks with their friends in another group consisting of students only. In this group, they discussed how they would execute the task. Precisely, this supported the previous study Omar et al. (2012) claiming that online discussions facilitate students to collaborate positively in executing tasks given by teachers. Likewise, online discussions became the best way for conducting tasks collaboration in this pandemic as students could freely talk and plan about their tasks without gathering physically.

\section{"Yes. Sometimes, we ask for submission deadline extension" \\ "Usually, I discuss the tasks with my friends in another group"}

Lastly, synchronous online discussion enables social supports during the instructional process (Hrastinski, 2008). Likewise, establishing social supports can be done through some ways like encouraging social interactions, affirming individuals' comments and developing use of informal language (Burnett, 2003). In the last session of the live-chat discussions, usually, the lecturer said thanks to students for joining and participating in the class. Hence, the students also responded by saying thanks and hopes. They also put thanking emoticon (folded hands) to show their emotional expressions. The participants believed that this situation makes students more engaged, active and motivated for joining the class. However, they argued that it also depends on the lecturer' attitudes and social interaction during the class. When the lecturer is able to make the lesson joyful and attractive, the students will be motivated to follow the lesson.

"Yes. But it depends on how the lecturer manages the class."

\section{Challenges in Synchronous Online Discussion}

Based on the virtual interviews, the researchers also found some problems faced by the students during the live-chat discussions. The problems were related to content and planning of tasks. As shown in Table 3, the problems appeared in Q \& A and in planning of tasks.

TABLE 3 | Challenges Found during Synchronous Online Discussion

\begin{tabular}{ll}
\hline Communication types & Key Issues \\
Content-related & Problems in Q \& A \\
Planning of tasks & Problems in planning tasks \\
\hline
\end{tabular}

Poor internet connection becomes the problem in delivering questions and answers. The participants claimed that sometimes their chats (questions or answers) were pending because of poor internet access at their homes. Likewise, this is a common problem in developing countries where technological devices and internet access are still limited (OwusuFordjour et al., 2020). In add, lots of chats in WAG often piled up and it made students to always scroll up the chats. In this case, the students have to find good internet access and use laptop/PC to make the scroll up process easier. Problems related to technical issue frequently appeared in technological-based learning. These findings supported previous study Jose and Abidin (2016) who discovered that some of their participants had to deal with slow internet network, system failure (computers or smartphones stopped working) and difficulty for locating other participants' posts. Hence, slow internet network and system failure obstructed them to perform speed/responsive writing as their chats were pending.

"I cannot follow the discussions completely when my internet access is getting worse. Only Edge (E) signal that I can find"

"Sometimes it is related to my understanding of the tasks. If I'm still unsure I ask my friends"

Then, a single displayed thread which led to difficulty in locating others' posts made the participants hard to always keep up with the discussions. Meanwhile, in planning of tasks the participants stated that sometimes they had different understanding about tasks given by the lecturer. To face this problem, they need to ask the class leader or the lecturer directly.

\section{CONCLUSION}

This study deals with exploration on how EFL university students perceived the employment of synchronous online discussion as a way of instructions. The findings of this study confirms that the students showed positive responses towards the employment of synchronous online discussion in their online class. The perceptions relate to some issues namely contentrelated, planning of tasks and social supports. In the issue of content-related, the students believed that synchronous online discussion (in form of live-chat discussions through WAG) was effective to teach their class. Synchronous online discussion facilitates them to deliver opinions, questions and answers as 
well as to get responses from the lecturer directly. Besides, critical thinking and writing skills including grammar and spelling can be improved through this way of teaching. For planning of tasks, synchronous online discussion allows students to negotiate tasks with the lecturer as well as planning tasks with their classmates. Lastly, the students agreed that synchronous online discussion provide live learning environment because they share emotional expressions in form of thanking emoticon, supports and hopes to WAG. This condition gives good psychological effects to the students. As a result, they will be more engaged, active and motivated to follow the discussions. However, the students also found some problems. Poor internet connection, lots of piled up chats, and misunderstanding of the tasks become challenges during the employment of synchronous online discussion (live-chat discussions).

Furthermore, the pedagogical implication of this study relates to the issue of maintaining language teaching process during the pandemic of Covid-19. Synchronous online discus-

\section{REFERENCES}

Arends, R. I. (1997). Classroom instruction and management (United States).

Burnett, C. (2003). Learning to chat: Tutor participation in synchronous online chat. Learning to chat: Tutor participation in synchronous online chat 8, 247-261.

Carliner, S. (2004). An overview of online learning (Armherst, MA: Human Resource Development Press).

Creswell, J. W. and Poth, C. N. (2016). Qualitative inquiry and research design: Choosing among five approaches (Sage publications).

Duemer, L., Fontenot, D., Gumfory, K., Kallus, M., Larsen, J., Schafer, S., et al. (2002). The use of online synchronous discussion groups to enhance community formation and professional identity development. The Journal of Interactive Online Learning 1, 1-12.

Ellis, R. A., Goodyear, P., Prosser, M., and O'Hara, A. (2006). How and what university students learn through online and face-to-face discussion: conceptions, intentions and approaches. Journal of Computer Assisted Learning 22, 244-256. doi: 10.1111/j.1365-2729.2006.00173.x.

Gulley, E. H. (1968). Discussion, conference, and group process (Holt, Rinehart and Winston).

Hamied, F. A. (2017). Research methods: A guide for first time researchers (Bandung: UPI Press)

Haythornthwaite, C. (2002). Building social networks via computer networks: Creating and sustaining distributed learning communities, Renninger, K. A. and Schumar, W. (eds.) (Cambridge University Press), 159-190.

Hrastinski, S. (2008). Asynchronous and synchronous e-learning. Educause quarterly $31,51-55$.

Jose, J. and Abidin, M. J. Z. (2016). A Pedagogical Perspective on Promoting English as a Foreign Language Writing through Online Forum Discussions. doi: 10.5539/elt.v9n2p84. https://dx.doi.org/10.5539/elt.v9n2p84.

Lee, L. (2002). Enhancing learners' communication skills through synchronous electronic interaction and task-based instruction. Foreign Language Annals 35, $16-24$.

Li, S., Zhao, X. D., and Zhao, R. (2005). On learner-centered teaching model and college English teaching reform. J]. Journal of Northeastern University (Social Science.

Liang, M. Y. (2010). Using synchronous online peer response groups in EFL writing: Revision-related discourse. Language Learning \& Technology 14, 45-64.

Liu, R., Qiao, X., and Liu, Y. (2006). A paradigm shift of learner-centered teaching style: reality or illusion. Journal of Second Language Acquisition and Teaching 13, 77-91.

Mackey, A. and Gass, S. M. (2005). Second Language Research: Methodology and Design (USA: Lawrence Erlbaum Associates).

Macknight, C. B. (2000). Teaching critical thinking through online discussions. Educause Quarterly 23, 38-41. sion offers some benefits that support the process of teaching English during this pandemic situation. In addition, postpandemic situation demands students, teachers, and lecturers to adapt with the changes of teaching modes from face-to-face classroom to online learning (Moorhouse, 2020). Therefore, we have to prepare for this challenge. Last of all the researchers suggested for further research to explore more about online learning in English language teaching. Asynchronous online learning and e-learning during this pandemic situation can be interesting topics to be discussed.

\section{ACKNOWLEDGMENTS}

The author would like to thank the Indonesia Endowment Fund for Education (LPDP) for their support on this study. The authors' special thanks is also delivered to any participants who willingly participated in this study.

Mayadas, F. (1997). Asynchronous Learning Networks: A Sloan Foundation Perspective. Journal of Asynchronous Learning Networks 1, 1-16.

Merriam, S. B. and Tisdell, E. J. (2016). Qualitative research-A guide to design and implementation (San Fransisco: John Wiley \& Sons).

Miles, M., Huberman, A. M., and Saldana, J. (2014). Qualitative data analysis: A methods sourcebook. The united states of America.

Miles, M. B. and Huberman, A. M. (1994). Qualitative data analysis: An expanded sourcebook (Sage Publications).

Moorhouse, B. L. (2020). Adaptations to a face-to-face initial teacher education course 'forced' online due to the COVID-19 pandemic. Journal of Education for Teaching, 1-3. doi: 10.1080/02607476.2020.1755205.

Murphy, K. and Collins, M. (1998). Development of communication conventions in instructional electronic chats. Journal of Distance Education 12, 177-200.

Nunan, D. (2012). Learner-centered English language education: The selected works of David Nunan (Routledge)

Omar, H., Embi, M. A., and Yunus, M. M. (2012). ESL Learners' Interaction in an Online Discussion via Facebook. Asian Social Science 8, 67-67. doi: 10.5539/ass.v8n11p67.

Owusu-Fordjour, C., Koomson, C. K., and Hanson, D. (2020). The impact of covid19 on learning-the perspective of the Ghanaian student. European Journal of Education Studies.

Parra, G. E. C. (2000). Learning English through online discussion groups. Journal of Adolescent \& Adult Literacy, 36-38.

Perveen, A. (2016). Synchronous and Asynchronous E-Language Learning: A Case Study of Virtual University of Pakistan. Open Praxis 8, 21-39. doi: 10.5944/openpraxis.8.1.212.

Ragupathi, K. (2018). Facilitating effective online discussions: Resource guide (Centre for Development of Teaching and Learning (CDTL)).

Saldana, J. (2011). Fundamentals of qualitative research (New York: Oxford University Press).

Salmon, G. (2013). E-tivities: The key to active online learning (Routledge).

Shahabadi, M. M. and Uplane, M. (2015). Synchronous and Asynchronous elearning Styles and Academic Performance of e-learners. Procedia - Social and Behavioral Sciences 176, 129-138. doi: 10.1016/j.sbspro.2015.01.453.

Sutherland-Smith, W. (2002). Integrating online discussion in an Australian intensive English language course. TESOL journal 11, 31-35.

Tuan, L. T. (2011). Negotiating tasks in EFL classrooms. Journal of Language Teaching \& Research 2.

Wdowik, S. (2014). Using a synchronous online learning environment to promote and enhance transactional engagement beyond the classroom. Using a synchronous online learning environment to promote and enhance transactional engagement beyond the classroom. Campus-Wide Information Systems.

Williams, L. and Lahman, M. (2011). Online Discussion, Student Engagement, and Critical Thinking. Journal of Political Science Education 7, 143-162. doi: $10.1080 / 15512169.2011 .564919$ 
Yin, R. K. (2016). Qualitative research from start to finish (Second) (New York: Guilford publications).

Conflict of Interest Statement: The authors declare that the research was conducted in the absence of any commercial or financial relationships that could be construed as a potential conflict of interest.
Copyright $\odot 2020$ Rinekso and Muslim. This is an open-access article distributed under the terms of the Creative Commons Attribution License (CC BY). The use, distribution or reproduction in other forums is permitted, provided the original author(s) and the copyright owner(s) are credited and that the original publication in this journal is cited, in accordance with accepted academic practice. No use, distribution or reproduction is permitted which does not comply with these terms. 